\title{
CATHERINE MAGNIEN-SIMONIN, Contributions imprimées éparses de Jean Dorat: supplément à l'inventaire de 2007
}

\author{
Filippo Fassina
}

\section{(2) OpenEdition}

\section{Journals}

\section{Edizione digitale}

URL: https://journals.openedition.org/studifrancesi/43744

DOI: 10.4000/studifrancesi.43744

ISSN: 2421-5856

\section{Editore}

Rosenberg \& Sellier

\section{Edizione cartacea}

Data di pubblicazione: 1 juin 2021

Paginazione: 208

ISSN: 0039-2944

\section{Notizia bibliografica digitale}

Filippo Fassina, «CATHERINE MAGNIEN-SIMONIN, Contributions imprimées éparses de Jean Dorat: supplément à l'inventaire de 2007», Studi Francesi [Online], 193 (LXV | I) | 2021, online dal 01 juillet 2021, consultato il 15 octobre 2022. URL: http://journals.openedition.org/studifrancesi/43744 ; DOI: https://doi.org/ 10.4000/studifrancesi.43744

Questo documento è stato generato automaticamente il 15 octobre 2022

\section{(c) (i) (9)}

Creative Commons - Attribuzione - Non commerciale - Non opere derivate 4.0 Internazionale - CC BY NC-ND 4.0

https://creativecommons.org/licenses/by-nc-nd/4.0/ 


\title{
CATHERINE MAGNIEN-SIMONIN,
} Contributions imprimées éparses de Jean Dorat: supplément à l'inventaire de 2007

\author{
Filippo Fassina
}

\section{NOTIZIA}

CATHERINE MAGNIEN-SIMONIN, Contributions imprimées éparses de Jean Dorat: supplément à l'inventaire de 2007, "Bibliothèque d'Humanisme et Renaissance", LXXXI, 3 (2019), pp. 497-506.

1 Dando seguito alla pubblicazione degli atti del convegno Jean Dorat poète humaniste de la Renaissance (Droz, 2007), l'A. riprende l'inventario dei testi a stampa di Dorat, ampliandolo sulla base della bibliografia più recente e delle risorse presenti in linea. In particolare, vengono aggiunte nove opere contenenti versi offerti da Dorat ai suoi contemporanei, mentre per tre testi, già citati nell'inventario del 2007, viene proposta una datazione differente. Di questi interventi di aggiornamento è fornita una breve descrizione, sia per quanto concerne le otto aggiunte, sia per i tre testi con una nuova datazione. L'A. inoltre specifica il criterio utilizzato per l'inserimento nell'inventario e, oltre al supplemento stesso, è presente un index nominum complementare relativo alle undici nuove opere repertoriate. 